\title{
Effect of maternal age on fetal outcome
}

\author{
Ushadevi G', Arul Anne Rose $\mathbf{S}^{2}$ \\ ${ }^{1}$ Dr Ushadevi Gopalan ,Associate Professor, Department of Obstetrics and Gynecology, ${ }^{2}$ Dr Arul Anne Rose S. Assistant \\ Professor, Department of Obstetrics and Gynecology. Both are affiliated with Tagore Medical College and Hospital, \\ Rathinamangalam, Chennai-127. INDIA
}

Address for Correspondence : Dr Ushadevi Gopalan, Associate Professor, Department of Obstetrics and Gynecology, Tagore medical college and hospital, Rathinamangalam, Chennai, E-mail: ushag7@ hotmail.com

\begin{abstract}
Introduction: Low birth weight is one of the most serious challenges in maternal and child health care in both developing and developed countries. Aim of the study: Our aim was to study the correlation between maternal age and fetal outcome measured in terms of fetal weight and perinatal mortality. Materials and Methods: This was a hospital based prospective study conducted in the department of obstetrics and gynecology in our teaching medical college and hospital over a period of 2 years extending from Jan 2011 - Dec 2012. All the cases delivering in this hospital were taken for this study. Total of about 1449 cases were taken for this study. Results: The average age of patients in this study was $23.92 \pm 4.09$. It was observed that there was an increase in birth weight with increasing age up to 40 years. The difference in birth weight between patients less than 20 years of age and in those between 20-29 years of age was found to be statistically significant $(\mathrm{p}<0.01)$ while no statistical significance was found in birth weight between the age group 20-29 and 30-39 years (p>0.05). There was an increase in perinatal mortality with increasing age with the least being in those patients less than 20 years of age. The difference in perinatal mortality between the different age groups was found to be statistically insignificant ( $\mathrm{p}>0.05$ ) Conclusion: Increasing maternal age was associated with increase in birth weight. There was no statistically significant association of maternal age with perinatal mortality rate.
\end{abstract}

Key words: Maternal Age, Birth Weight, Perinatal Mortality

\section{Introduction}

Our country being vast and divided into so many regions with different cultural, ethnic and nutritional background the limits of normal parameters like optimum fetal birth weight, acceptable perinatal mortality and morbidity in relation to maternal age has not been standardized. Because of the regional variations and also because of the fact that we are not able to set standard parameters we aim to undertake this study. Low birth weight is one of the most serious challenges in maternal and child health care in both developing and developed countries. Low birth weight is the main contributing factor in perinatal mortality and morbidity [1,2] and LBW newborns are at higher risk for perinatal and infant mortality [ $3,4,5]$. Birth weight is a good gauge of health of the child in the womb because the weight is taken immediately after birth.

The impact that the decision to delay childbearing has on maternal and perinatal outcomes becomes very relevant

Manuscript received: $1^{\text {st }}$ Apr 2015

Reviewed: $18^{\text {th }}$ Apr 2015

Author Corrected: $4^{\text {th }}$ May 2015

Accepted for Publication: $13^{\text {th }}$ May 2015 nowadays as more women postpone childbearing until they are over the age of 35 . There are numerous reports in the literature assessing the effect of advanced maternal age on pregnancy outcomes but results are varied [6,7]. One of the most striking changes in the demography of developed countries during the last 20 years has been the postponement of childbirth until women are in their late 30's[8]. In the Indian scenario, the NFHS 3 reports association of low birth weight with age of mother [9].

The present study is aimed to study the correlation between maternal age with fetal outcome measured in terms of fetal weight and perinatal mortality

\section{Materials and Methods}

The work was started after obtaining ethical committee clearance. Informed consent was obtained from each patient before taking part in the study. This was a hospital based prospective study conducted in the department of obstetrics and gynecology in our teaching medical college and hospital over a period of 2 years extending from Jan 2011 - Dec 2012. All the cases delivering in this hospital

Available online at: www.ijmrr.in 390 | P a g e 


\section{Research Article}

were taken for this study. Total of about 1449 cases were taken for this study. The patients were from both rural and urban areas. A detailed history including past and present history was taken from each patient and a thorough physical examination was done and basic investigations were done for all patients. Data was collected on a structured, predesigned and pretested questionnaire. The emphasis was on maternal age at the start of pregnancy .

The period of gestation was calculated from the first day of the last menstrual period, using the simple Naegle's rule and it was recorded in completed weeks Confirmation of gestational age was done in all babies

\section{Result}

Table 1-Relationship of maternal age with mean birth weight and PNMR

\begin{tabular}{|c|c|c|c|c|c|c|}
\hline Age group & Number & Percentage & $\begin{array}{l}\text { Mean birth } \\
\text { weight }\end{array}$ & P value & PNMR* & P value \\
\hline$<20$ & 145 & 10.01 & $2.481 \pm 0.568$ & \multirow[b]{2}{*}{$P<0.01$} & $2.07 \%$ & \multirow{4}{*}{$\mathrm{P}>0.05$} \\
\hline $20-29$ & 1144 & 78.95 & $\begin{array}{l}2.618 \pm \\
0.562\end{array}$ & & $3.50 \%$ & \\
\hline $30-39$ & 159 & 10.97 & $2.629 \pm 0.636$ & \multirow{2}{*}{$P>0.05$} & $5.66 \%$ & \\
\hline$>40$ & 1 & 0.07 & & & & \\
\hline
\end{tabular}

*Perinatal mortality rate

Table-1 shows the relationship of maternal age with mean birth weight and perinatal mortality rate. The average age of patients in this study was $23.92 \pm 4.09$ in years. The single largest group of mothers was in the age group of 20-29 years. Of the 1449 patients included in this study, $10.01 \%$ were less than 20 years of age, $78.95 \%$ were between $20-29$ yrs of age, $10.97 \%$ were between $30-39$ years and $0.07 \%$ was found to be more than 40 years. The mean birth weight was found to be $2.481 \pm 0.568$ in kilograms in patients less than 20 years and it was $2.618 \pm 0.562$ kilograms and $2.629 \pm 0.636$ kilograms in the age group 20-29 years and 30-39 years respectively. It was observed that there was an increase in birth weight with increasing age up to 40 years. The difference in birth weight between patients less than 20 years of age and in those between 20-29 years of age was found to be statistically significant $(\mathrm{p}<0.01)$ while no statistical significance was found in birth weight between the age group 20-29 years and 30-39 years ( $p>0.05)$.

It was found there was an increase in perinatal mortality with increasing age with the least being in those patients less than 20 years of age. The perinatal mortality in the age group of less than 20 years was $2.07 \%$ while in the age group of 20-29 years it was found to be $3.5 \%$ and in the age group 30-39 years it was 5.66\%. In spite of this, the difference in perinatal mortality between the different age groups was found to be statistically insignificant $(\mathrm{p}>0.05)$.

\section{Discussion}

Various maternal factors have varying degrees of influence on the ultimate outcome of the fetus in relation to its birth weight. The degree of influence each maternal factor has on intrauterine growth however varies. The mean birth weight in this study was $2.61 \pm 0.58 \mathrm{~kg}$. As mentioned earlier these weights were obtained within an hour of delivery and hence the postnatal loss of weight did not account for any decrease in weight. The single largest groups of mothers were in the age group of 20-29 years which correspond to the average reproductive profile of the country. Mothers in the age group less than 20 years had the lowest birth weight. The mean birth

weight was found to increase upto the age of 40 years. This was also demonstrated by Pachauri et al [11], and Ghosh et al [12]. They found a decline in birth weight after the age of 40 years. This could not be demonstrated in our study as there was only one patient in the age group more than 40 years. This study corroborates with that of Bhargava et al [13], Khatua [14] and Ghai [15] who found that the incidence of low birth weight infants was higher in mothers less than 20 years of age. Leppert et al [16] found that maternal age remains a significant predictor of birth weight but Cooper et al [17] reported that maternal age was not an independent risk factor for Small for 
gestational age babies. Gortzak et al [18] found that teenage pregnancy was associated with low birth weight while Bereczky et al [19] reported a highly significant decrease of mean fetal weight in those aged more than 35 yrs. Another study suggested that causation of LBW is maternal age $(<18$ yrs and $>35 y r s)[20]$.

Mwabu(2008) and Okurut(2009)found mother's age to have positive significant impact on birth weight.[21,22]. The positive association between maternal age and LBW which is largely due to the health depreciation effect is consistent with Vahdaninia et al(2008)who found same for Iran[23]. In a study by P.De Carvalho et al it was found that maternal age contributed negatively to birth weight [24]. In contrast Fedrick [25] and Dougherty and Jones [26] found that age was not a significant factor in determining the birth weight of babies. In a study by Gagan Agarwal et al [27] the prevalence of LBW among mothers aged $<18$ yrs was $42.86 \%$ and those $>35$ years $33.33 \%$. A LBW prevalence of $39.1 \%$ was found in urban areas of Delhi, the maternal age was identified as a significant determinant [28]

A significant difference in the perinatal mortality was observed in the 31 years and above group compared with those less than 30 years in a perinatal mortality survey in India [29]. An increase in perinatal mortality rate with increasing age was found in our study, but the difference was not found to be statistically significant. Reichman and Pagnini [30] found that risk of infant mortality increased with increasing age of the mother .Yoder and Young [31] found no difference in the incidence of low birth weight or neonatal survival in the different age groups. DuPlessis et al [32] found that maternal age at delivery is significantly associated with low birth weight and premature births but they found no relationship between maternal age and infant mortality. In a study by Hansen [33] it was found that the still birth rate seems to double by the late 30 's. In our study the perinatal mortality was found to be double in the age group 30-39 (56.6 / 1000 live births ) compared to that of the age group less than 20 years $(20.68 / 1000$ live births ) but the difference was not statistically significant .

Funding: Nil, Conflict of interest: None initiated. Permission from IRB: Yes

\section{References}

1. Shah KP, Shah PM. Relation of maternal nutrition and low birth weight. Indian Pediatr. 1979 Nov;16(11):961-6.

2. Bhatia BD, Tyagi NK. Maternal determinants of birth weight-A multivariate analysis. Indian Pediatr. 1984 May;21(5):365-71.

International Journal of Medical Research and Review
3. United Nations Children's fund and WHO, Low birth weight:Country,regional and global estimates, INICEF, New York,2004 Available onlie at: whqlibdoc.who.int/publications/2004/9280638327.pdf cited on $20^{\text {th }}$ april 2015.

4. Mondal B, Risk factors for low birth weight in Nepali infants. Indian J Pediatr. 2000 Jul;67(7):477-82.

5. Villar J, Bellizan J. The relative contribution of prematurity and fetal growth retardation-low birth weight in developing and developed societies. Am J Obstet Gynecol. 1982 Aug 1;143(7):793-8.

6. Russell RB, Petrini JR, Damus K, Mattison DR, Schwarz RH. The changing epidemiology of multiple births in the United States. Obstet Gynecol. 2003 Jan;101(1):129-35.

7. Seoud M, Nassar AH, Usta IM, Melhem Z, Kazma A, Khalil AM. Impact of advanced maternal age on pregnancy outcome . Am J Perinatol. 2002 Jan;19(1):1-8.

8. Tough SC, Newburn -Cook C, Johnston DW, Svenson LW, Rose S, Belik J.Delayed childbearing and its impact on population rate changes in lower birth weight, multiple births, and preterm delivery. Pediatrics. 2002 Mar;109(3):399-403.

9.http://hetv.org/india/nfhs/nfhs3/NFHS-3-Chapter-09-

Child-Health.pdf

10.Dubowitz LMS, Dubowitz V, Goldberg C. Clinical assessment of gestational age in the new born infant. J Pediatr. 1970 Jul;77(1):1-10.

11. Pachauri S, Marwah SM. A Study of the effect of certain maternal factors on birth weight. Indian J Med Sci. 1970 Oct;24(10):650-60.

12. Ghosh S, Hooja V, Mittal SK, Verma RK. Biosocial determinants of birth weight. Indian Pediatr. 1977 Feb;14(2):107-14.

13. Bhargava SK, Bhargava K, Kumari S et al. Birth weight, gestational age and maternal factors in low birth weight babies . Indian Pediatr. 1973 Mar;10(3):161-6.

14. Khatua SP, Manocha BK, Chatterjee S, Roy Palodhi PK. The incidence and etiology of small for date infants born at term. Indian Pediatr. 1979 May;16(5):395-402. 


\section{Research Article}

15. Ghai OP. Maternal factors in the epidemiology of low birth weight. Indian J Pediatr. 1980 MarApr;47(385):123-8.

16. Leppert PC, Namerow PB, Barker D .Pregnancy outcomes among adolescent and older women receiving comprehensive prenatal care .J Adolesc Health care .1986 Mar;7(2):112-7.

17. Cooper LG, Leland NL, Alexander G. Effect of maternal age on birth outcomes among young adolescents. Soc Biol.1995 Spring-Summer ;42(1-2):2235 .

18. Gortzak-Uzan L, Hallak M, Press F, Katz M , Shoham-Vardi I. Teenage pregnancy: Risk factors for adverse perinatal outcome .J Matern Fetal Med .2001Dec ;10(6):393-7.

19. Bereczky LK, Kiss SL, Szabo B. Increased frequency of gestational and delivery related complications in women of 35 years and above .J Obstet Gynaecol.2015 Feb;35(2):115-20.

20. Paul VK .Textbook of preventive and social medicine. In: Gupta P, Ghai OP, editors. Child Health: Newborn care in India, 2nd ed. New Delhi: CBS publishers. 2007: p. $383-84$.

21. Mwabu, Germano. .'The Production of Child Health in Kenya: A Structural Model of Birth Weight”. Yale University Economic Growth Center Discussion Paper. New Haven :Yale Economics Department Working Paper No .52,2008.

22. Okurut F.N.Determinants of Birth Weight in Botswana. A Paper presented at the CSAE Conference, $22^{\text {nd }}-24^{\text {th }}$ march 2009 , University of Oxford, UK.

23. Vahdaninia, M.Tavafian, S.S. and Montazeri, A. Correlates of Low Birth Weight in Term Pregnancies : A retrospective Study from Iran .BMC Pregnancy and Childbirth.2008;8:12.
24. P. De Carvalho Padilha, E.Accioly,C.Chagas, E.Portela, C.L.Da Silva y C.Saunders .Birth weight variation according to maternal characteristics and gestational weight gain in Brazilian women .Nutr Hosp.2009;24(2):207-12.

25. Fedrick J, Adelstein P. Factors associated with low birth weight of infants delivered at term. Br J Obstet Gynaecol. 1978 Jan;85(1):1-7.

26. Dougherty CRS, Jones AD .The determinants of birth weight. Am J Obstet Gynecol. 1982 Sep 15;144(2):190200 .

27. Gagan A, Sartaj A, Kapil G, Vijay Kumar, Parul G, et al. Maternal Risk Factors Associated with Low Birth Weight Neonates in a Tertiary Care Hospital, Northern India. J Community Med Health Educ 2012; 2:177. doi: 10.4172/2161-0711.1000177

28. Chhabra P, Sharma AK, Grover VL, Aggarwal OP. Prevalence of low birth weight and its determinants in an urban resettlement area of Delhi. Asia Pac J Public Health. 2004;16(2):95-8.

29. Mehta A, Jayant K. Perinatal mortality survey in India: Identification of health intervention needs. J Obstet Gynaec India .1981; 31: 183-215.

30. Reichman NE, Pagnini DL. Maternal age and birth outcomes: Data from New Jersey .Fam plann Perspect .1997; 29(6):268-72, 295.

31. Yoder BA, Young MK .Neonatal outcomes of teenage pregnancy in a military population .Obstet Gynecol.1997 Oct; 90(4 pt 1):500-6.

32. DuPlessis HM, Bell R, Richards T. Adolescent pregnancy: Understanding the impact of age and race on outcomes.J Adolesc Health 1997 Mar; 20(3): 187-97.

33. Hansen JP. Older maternal age and pregnancy outcome- A review of the literature. Obstet Gynecol Surv. 1986 Nov;41(11):726-42..

\section{How to cite this article?}

Ushadevi G, Arul Anne Rose S . Effect of maternal age on fetal outcome. Int J Med Res Rev 2015;3(4):390-393. doi: 10.17511/ijmrr.2015.i4.073. 